
излечения у впервые выявленных больных деструктивным туберкулезом легких с позиций доказательной медицины

ГБОУ ВПО "Московский государственный медико-стоматологический университет" Минздравсоцразвития России: 127473, Москва, ул. Делегатская, 20 / 1

\title{
V.Yu.Mishin, A.S.Kononets \\ Evidence-based efficacy of chemotherapy and stability of clinical cure in newly diagnosed patients with cavitary pulmonary tuberculosis
}

\begin{abstract}
Summary
A randomized multi-center clinical study of chemotherapy efficacy, clinical cure and early recurrence rate involved 240 newly diagnosed patients with cavitary pulmonary tuberculosis treated in municipal and penitentiary medical facilities. Given the primary multiple drug resistance (MDR) of 22.5-33.3\%, intensive chemotherapy with isoniazid, rifampicin, pyrazinamide, ethambutol, kanamycin (or amikacin) and ofloxacin (or levofloxacin) allowed to achieve sputum conversion in $100 \%$ of smear-positive patients using sputum microscopy and in $89.2 \%$ using sputum culture, cavity closure in $71.7 \%$, and clinical cure in $94.2 \%$ with early recurrence rate of $2.6 \%$ in comparison to $54.2,45.8,45.8,65$ and $20.5 \%$ respectively in patients treated with isoniazid, rifampicin, pyrazinamide and ethambutol. Lung fibrocavitary lesions with high level of MDR developed in $55 \%$ of patients and were associated with high cost of treatment due to the need in expensive salvage chemotherapy regimens and high-tech surgical interventions.

Key words: pulmonary tuberculosis, drug resistance, chemotherapy, evidence-based medicine.
\end{abstract}

\section{Резюме}

Было проведено рандомизированное многоцентровое клиническое исследование эффективности химиотерапии, клинического излечения и частоты ранних рецидивов у 240 впервые выявленных больных деструктивным туберкулезом легких в гражданских и пенитенциарных противотуберкулезных учреждениях. Доказано, что при уровне первичной множественной лекарственной устойчивости (МЛУ) $22,5-33,3 \%$ режим химиотерапии изониазидом, рифампицином, пиразинамидом, этамбутолом, канамицином (амикацин) и офлоксацином (левофлоксацин) в интенсивной фазе лечения позволяет добиться прекращения бактериовыделения по результатам микроскопии мокроты у $100 \%$ больных и по посеву - у 89,2 \%, закрытия каверн - у 71,7 \%, клинического излечения - у $94,2 \%$ и ранних рецидивов - у 2,6 \% пациентов. В то время как режим химиотерапии изониазидом, рифампицином, пиразинамидом, этамбутолом - у 54,2 ; 45,$8 ; 45,8 ; 65$ и 20,5\% больных соответственно. При этом в $55 \%$ случаев констатировано формирование фиброзно-кавернозного туберкулеза с высоким уровнем вторичной МЛУ, что требует больших экономических затрат на дорогостоящие резервные препараты и высокотехнологичные оперативные вмешательства.

Ключевые слова: туберкулез легких, лекарственная устойчивость микобактерий туберкулеза, химиотерапия туберкулеза, доказательная медицина.

Клиническое излечение впервые выявленных больных деструктивным туберкулезом легких является актуальной проблемой фтизиатрии в виду тяжелого течения заболевания, высокого риска развития множественной лекарственной устойчивости (МЛУ) микобактерий туберкулеза (МБТ), возможности формирования хронического фиброзно-кавернозного туберкулеза с высокой эпидемиологической опасностью для здорового населения [1-4].

Для лечения впервые выявленных больных деструктивным туберкулезом легких в соответствии с приказом МЗ РФ № 109 от 21.03.03 [5] и Национальным руководством по фтизиатрии 2007 г. [3] определен I режим химиотерапии (I PXT), состоящий из основных противотуберкулезных препаратов: изониазида, рифампицина, пиразинамида, стрептомицина (этамбутола). При этом клиническое излечение пациентов, зарегистрированных в 2009 г., соста- вило всего 31,5 \%, а фиброзно-кавернозный туберкулез у них сформировался в 45,5\% случаев [6-8].

Столь низкая эффективность лечения связана, в первую очередь, с повсеместным использованием оказавшегося неадекватным в РФ I РXT [2, 3, 9], применение которого только за 7 лет привело к значительному увеличению первичной и вторичной МЛУ МБТ. Так, если в 2003 г. уровень первичной МЛУ МБТ составлял 8,3 \%, то в 2010 г. - уже 17,3\%, т. е. вырос более чем в 2 раза. В то же время значительно увеличился уровень вторичной МЛУ как показатель неэффективности I РXТ с 15,5 \% в 2003 г. до 22,3 \% в 2010 г. При этом в 2007-2010 гг. в РФ не было ни одного Федерального округа с уровнем первичной МЛУ < $10 \%$ [6-8]. Такой высокий уровень первичной МЛУ МБТ, как правило, сочетается с высоким уровнем моно- и полирезистентности, в т. ч. к изониазиду и другим основным препаратам 
у 22,2-44,3 \% больных, а к рифампицину - у 11,3$25,3 \%[10-14]$.

Приказом МЗ РФ № 109 от 21.03.03 [5], Национальным руководством по фтизиатрии 2007 г. и Методическими рекомендациями ФСИН Минюста РФ для лечения впервые выявленных больных деструктивным туберкулезом легких с высоким риском развития первичной МЛУ МБТ и в регионах, где первичная МЛУ превышает $5 \%$, рекомендован также ІІБ РХТ, состоящий из изониазида, рифампицина, пиразинамида, этамбутола, канамицина (амикацина) и фторхинолона $[3,5,15]$. Основная роль в эффективности ІІБ РХТ определяется бактерицидным действием фторхинолонов, их синергетическим действием с другими основными препаратами и низкой частотой нежелательных эффектов [1-3, 16-33].

Для доказательства эффективности РXТ еще в 70-Х гг. XX столетия отечественными фтизиатрами впервые в мире была разработана методика многоцентровых контролируемых клинических исследований, которая усовершенствована в I десятилетии XXI в. с позиций доказательной медицины и позволяет обосновывать наиболее оптимальные комбинации препаратов для лечения впервые выявленных больных туберкулезом [33-42].

Длительное время только рекомендации по лечению туберкулеза Американского торакального общества были основаны на контролируемых клинических исследованиях с позиций доказательной медицины, когда к практическому использованию предлагались лишь те рекомендации, которые имеют самые высокие AI- или AII-категории доказательства [43]. Всемирная организация здравоохранения в рекомендациях по лечению туберкулеза перешла на эту методику только в 2009 г. [44].

В отдельных регионах РФ в гражданском и пенитенциарном секторе здравоохранения в 2003-2010 гг. были проведены клинические исследования сравнительной эффективности ІІБ и I РХТ в интенсивную фазу лечения впервые выявленных больных деструктивным туберкулезом легких, в которых активно участвовали авторы данной статьи. При этом было установлено, что прекращение бактериовыделения при ІІБ РХТ достигнуто более чем у 80 \% больных, а закрытие каверн в легких - у $50 \%$. В то же время использование I РXТ вело к снижению этих показателей более чем в 2-3 раза $[10-14,16-19,21,22$, 24-27, 35-38, 40-43]. К глубокому сожалению, в РФ в 2008-2010 гг. при уровне первичной лекарственной устойчивости МБТ 33,2-36,8 \% и первичной МЛУ 13,6-17,3 \% ІІБ РХТ использовался только у 8,19,3\% впервые выявленных больных туберкулезом. В то же время I PXТ продолжает оставаться основным и использоваться в 73,1-71,5 \% случаев, что ведет к дальнейшему снижению эффективности лечения и накоплению в контингентах противотуберкулезных диспансеров большого числа неизлечимых больных с фиброзно-кавернозным туберкулезом легких с массивным выделением МЛУ МБТ к основным и резервным препаратам [6-8]. Вместе с тем в отечественной литературе полностью отсутствуют публикации об эффективности основного курса лечения и стойкости клинического излечения у впервые выявленных больных деструктивным туберкулезом легких в гражданских и пенитенциарных противотуберкулезных учреждениях, лечившихся в интенсивной фазе химиотерапии ІІБ или I PXТ, с позиций доказательной медицины.

Целью исследования было изучение сравнительной эффективности ІІБ и I РХТ в интенсивную фазу химиотерапии, стойкости клинического излечения и частоты ранних рецидивов у впервые выявленных больных деструктивным туберкулезом легких в гражданских и пенитенциарных противотуберкулезных учреждениях с позиций доказательной медицины.

\section{Материалы и методы}

Было проведено рандомизированное контролируемое клиническое исследование (по единому протоколу) 240 пациентов с туберкулезом легких в возрасте от 20 до 60 лет. Среди них мужчин было 187, женщин - 53. В исследование были включены ВИЧотрицательные впервые выявленные больные деструктивным туберкулезом легких с выделением МБТ, выявляемых при микроскопии и посеве мокроты на питательные среды, никогда не лечившиеся противотуберкулезными препаратами. При этом 120 больных лечились в гражданских противотуберкулезных диспансерах (ПТД) г. Москвы, Московской, Смоленской, Кировской и Кемеровской областей, где уровень первичной МЛУ МБТ составлял от 9,1 до $22,7 \%$ [4, 25, 29], и 120 - в пенитенциарных противотуберкулезных стационарах (ПТС) Федеральной системы исполнения наказаний (ФСИН) Воронежской, Ивановской, Кировской и Нижегородской областей, где уровень первичной МЛУ МБТ - от 15,8 до $29 \%[4,9,25,29]$. Больные, лечившиеся как в ПТД, так и в ПТС ФСИН, были рандомизированы на 2 группы по применяемому РХТ. Основную группу составили 120 больных, которым в интенсивной фазе лечения назначался ІІБ РХТ, состоящей из комбинации изониазида, рифампицина, пиразинамида, этамбутола, канамицина (или амикацина) и фторхинолона (офлоксацина или левофлоксацина). В группу сравнения вошли также 120 больных, которые получали I PXT, состоящей из комбинации изониазида, рифампицина, пиразинамида и этамбутола (или стрептомицина).

После получения микробиологических данных о лекарственной чувствительности МБТ производилась коррекция химиотерапии с отменой основных противотуберкулезных препаратов, к которым была выявлена устойчивость, и заменой их резервными. При этом основное внимание уделялось контролируемому приему препаратов под непосредственным медицинским наблюдением. Результаты лечения оценивались по клиническим, микробиологическим и рентгено-томографическим показателям через 3 и 12 мес. лечения, а также через 1-2 года диспансерного наблюдения для оценки стойкости клинического излечения. 


\section{Результаты и обсуждение}

Группы пациентов были практически идентичны по возрастным, половым, клинико-рентгенологическим и микробиологическим параметрам. В табл. 1 представлено распределение больных по клиническим формам туберкулеза легких. Из табл. 2 следует, что у пациентов, лечившихся как в ПТД, так и в ПТС ФСИН, преимушественной клинической формой был инфильтративный туберкулез легких (79,2 \% и 76,7 \% случаев соответственно; $p>0,05)$. В то же время у больных ПТС ФСИН казеозная пневмония была диагностирована в 2,4 раза чаще (14,1\% случаев), чем у больных ПТД $(5,8 \% ; p<0,05)$. При этом распределение больных в ПТД и ПТС ФСИН по клиническим формам в основной группе, лечившихся ІІБ РХТ, и группе сравнения, лечившихся I PXT, было практически одинаковым $(p<0,05)$.

Клиническая форма туберкулеза не всегда отражает распространенность инфильтративно-деструктивных изменений в легких, поэтому в табл. 2 представлено распределение больных по распространенности процесса и размерам каверн в легких в наблюдаемых группах. Как видно из табл. 2, у больных ПТД в 35,8 \% случаев специфический процесс ограничен 1 долью легкого, что оказалось в 3,3 раза больше, чем у пациентов ПТС ФСИН $(10,8 \% ; p<0,05)$. В то же время распространенность туберкулезных изменений на $\geq 3$ долей легких наблюдалось в ПТС ФСИН у 24,2 \% больных, что в 2,1 раза больше, чем у пациентов ПТД $(11,7 \% ; p<0,05)$. При этом распределение больных в ПТД и ПТС ФСИН по распространенности процесса в легких в основной группе и группе сравнения было практически одинаковым $(p<0,05)$.

Аналогичная ситуация прослеживалась в наблюдаемых группах и по размерам каверн в легких (табл. 2).
У больных ПТД каверны в легких $<2$ см в диаметре диагностированы в 45,8 \% случаев, что в 1,8 раза больше, чем у пациентов ПТС ФСИН $(25 \% ; p<0,05)$. И наоборот, больных ПТС ФСИН с кавернами $>4$ см в диаметре было в 2,4 раза больше (14,2 \%), чем пациентов ПТД $(5,8 \% ; p<0,05)$. В то же время распределение больных в ПТД и ПТС ФСИН по размерам каверн в легких в основной группе и группе сравнения было практически одинаковым $(p<0,05)$.

Таким образом, контингент больных в ПТС ФСИН был существенно тяжелее по преобладанию количества больных с казеозной пневмонией с распространенным процессом и большими кавернами в легких, что позволило сравнить эффективность ІІБ и I PXТ при различной тяжести течения впервые выявленного деструктивного туберкулеза легких. Следует отметить, что распределение больных в основной группе, лечившихся ІІБ РХТ, и группе сравнения, лечившихся I РXТ, как в ПТД, так и в ПТС ФСИН было практически одинаковым.

В табл. 3. представлено распределение больных по частоте и характеру первичной лекарственной устойчивости МБТ. Как следует из табл. 3, в ПТД чувствительность МБТ к противотуберкулезным препаратам была сохранена у 55 \% больных, лекарственная устойчивость выявлялась у $45 \%$. В ПТС ФСИН чувствительные МБТ были выявлены у $32,5 \%$, а устойчивые - у 67,5 \%, что было соответственно в 1,7 раза меньше и в 1,5 раза больше $(p<0,05)$. При этом обращает на себя внимание более высокий (на $10,8 \%)$ уровень первичной МЛУ в ПТС ФСИН $(33,3 \%)$, по сравнению с пациентами ПТД $(22,5 \%$; $p<0,05)$.

Следовательно, уровень первичной лекарственной устойчивости МБТ, в т. ч. МЛУ у больных ПТС ФСИН, был более высоким, что позволило сравнить

Таблица 1

Распределение больных по клиническим формам туберкулеза легких

\begin{tabular}{|c|c|c|c|c|c|}
\hline \multirow[t]{2}{*}{ Лечебное учреждение } & \multirow[t]{2}{*}{ PXT } & \multirow[t]{2}{*}{ Абс. } & \multicolumn{3}{|c|}{ Клинические формы } \\
\hline & & & $\begin{array}{c}\text { диссеминированный туберкулез, } \\
n(\%)\end{array}$ & $\begin{array}{c}\text { инфильтративный туберкулез, } \\
\text { n (\%) }\end{array}$ & $\begin{array}{c}\text { казеозная пневмония, } \\
n(\%)\end{array}$ \\
\hline \multirow[t]{3}{*}{ птД } & ІІБ & 60 & $8(13,3 \pm 4,4)$ & $48(80,0 \pm 5,1)$ & $4(6,7 \pm 3,2)$ \\
\hline & I & 60 & $10(16,7 \pm 4,8)$ & $47(78,3 \pm 5,3)$ & $3(5,0 \pm 2,8)$ \\
\hline & Всего & 120 & $18(15,0 \pm 3,2)$ & $95(79,2 \pm 3,7)$ & $7(5,8 \pm 2,1)$ \\
\hline \multirow[t]{3}{*}{ птС ФСИн } & ІІБ & 60 & $6(10,0 \pm 3,8)$ & $45(75,0 \pm 5,5)$ & $9(15,0 \pm 4,6)$ \\
\hline & I & 60 & $5(8,3 \pm 3,4)$ & $47(78,3 \pm 5,3)$ & $8(13,3 \pm 4,4)$ \\
\hline & Всего & 120 & $11(9,2 \pm 2,6)$ & $92(76,7 \pm 3,9)$ & $17(14,1 \pm 3,1)$ \\
\hline
\end{tabular}

Таблица 2

Распределение больных по распространенности процесса и по размерам каверн в легких

\begin{tabular}{|c|c|c|c|c|c|c|c|c|}
\hline \multirow[t]{2}{*}{ Лечебное учреждение } & \multirow[t]{2}{*}{ PXT } & \multirow[t]{2}{*}{ Абс. } & \multicolumn{3}{|c|}{ Распространенность, $n$ (\%) } & \multicolumn{3}{|c|}{ Каверны, $n$ (\%) } \\
\hline & & & $\leq 1$ доли & 2 доли & $\geq 3$ долей & $<2 \mathrm{~cm}$ & $2-4 \mathrm{~cm}$ & $>4 \mathrm{~cm}$ \\
\hline \multirow[t]{3}{*}{ птд } & ІІБ & 60 & $19(31,7 \pm 6,0)$ & $33(55,0 \pm 6,4)$ & $8(13,3 \pm 6,4)$ & $28(46,7 \pm 6,4)$ & $28(46,7 \pm 6,4)$ & $4(6,7 \pm 3,2)$ \\
\hline & I & 60 & $24(40,0 \pm 6,3)$ & $30(50,0 \pm 6,5)$ & $6(10,0 \pm 3,9)$ & $27(45,0 \pm 6,4)$ & $30(50,0 \pm 6,4)$ & $3(5,0 \pm 2,8)$ \\
\hline & Всего & 120 & $43(35,8 \pm 4,4)$ & $63(52,5 \pm 4,5)$ & $14(11,7 \pm 2,9)$ & $55(45,8 \pm 4,5)$ & $58(48,3 \pm 4,5)$ & $7(5,8 \pm 2,1)$ \\
\hline \multirow[t]{3}{*}{ птс ФСИН } & ІІБ & 60 & $5(8,3 \pm 3,5)$ & $40(66,7 \pm 5,0)$ & $15(25,0 \pm 5,6)$ & $14(23,3 \pm 5,4)$ & $37(61,7 \pm 6,2)$ & $9(15,0 \pm 4,6)$ \\
\hline & I & 60 & $8(13,3 \pm 4,4)$ & $38(63,3 \pm 5,3)$ & $14(23,3 \pm 5,4)$ & $16(26,7 \pm 5,7)$ & $36(60,0 \pm 6,3)$ & $8(13,3 \pm 4,4)$ \\
\hline & Всего & 120 & $13(10,8 \pm 2,8)$ & $78(65,0 \pm 4,3)$ & $29(24,2 \pm 3,9)$ & $30(25,0 \pm 4,0)$ & $73(60,8 \pm 4,4)$ & $17(14,2 \pm 3,2)$ \\
\hline
\end{tabular}


Таблица 3

Распределение больных по частоте и по характеру лекарственной чувствительности МБТ

\begin{tabular}{|c|c|c|c|c|c|c|}
\hline \multirow[t]{2}{*}{ Лечебное учреждение } & \multirow[t]{2}{*}{ PXT } & \multirow[t]{2}{*}{ Абс. } & \multicolumn{4}{|c|}{ Лекарственная чувствительность, $n$ (\%) } \\
\hline & & & лч & MP & $\Pi$ П & млу \\
\hline \multirow[t]{3}{*}{ птД } & ІІБ & 60 & $34(56,7 \pm 6,4)$ & $4(6,7 \pm 3,2)$ & $8(13,3 \pm 5,7)$ & $14(23,3 \pm 3,9)$ \\
\hline & I & 60 & $32(53,3 \pm 6,4)$ & $6(10,0 \pm 3,9)$ & $9(15,0 \pm 5,5)$ & $13(21,7 \pm 4,4)$ \\
\hline & Всего & 120 & $66(55,0 \pm 4,5)$ & $10(8,3 \pm 2,5)$ & $17(14,2 \pm 3,2)$ & $27(22,5 \pm 3,8)$ \\
\hline \multirow[t]{3}{*}{ ПтС ФСИН } & ІІБ & 60 & $19(31,6 \pm 6,0)$ & $6(10,0 \pm 3,9)$ & $14(23,3 \pm 5,4)$ & $21(35,0 \pm 6,1)$ \\
\hline & I & 60 & $20(33,3 \pm 6,1)$ & $7(11,6 \pm 4,1)$ & $14(23,3 \pm 5,4)$ & $19(31,7 \pm 6,0)$ \\
\hline & Всего & 120 & $39(32,5 \pm 4,3)$ & $13(10,8 \pm 2,8)$ & $28(23,3 \pm 3,9)$ & $40(33,3 \pm 4,3)$ \\
\hline
\end{tabular}

Примечание: ЛЧ - лекарственная чувствительность сохранена, МР - монорезистентность, ПР - полирезистентность.

эффективность ІІБ и І РХТ при различной частоте лекарственной устойчивости МБТ. При этом распределение больных в ПТД и ПТС ФСИН по частоте и характеру лекарственной чувствительности МБТ в основной группе и группе сравнения было практически одинаковым $(p<0,05)$.

Таким образом, больные основной группы, лечившиеся ІІБ РХТ, и пациенты группы сравнения, лечившиеся I PXТ, как в ПТД, так и ПТС ФСИН были практически идентичны по клиническим и микробиологическим параметрам, что позволило объективно оценить эффективность ІІБ и I РХТ при лечении впервые выявленных больных деструктивным туберкулезом легких с различной тяжестью течения болезни и различным уровнем первичной лекарственной устойчивости МБТ.

В табл. 4 представлена эффективность лечения по показателю прекращения бактериовыделения на основании микроскопии и посева на питательные среды через 3 мес. интенсивной фазы химиотерапии. Как видно из табл. 4, через 3 мес. лечения прекращение бактериовыделения по микроскопии мокроты было достигнуто у 100 \% больных основной группы, лечившихся ІІБ РХТ, в ПТД и ПТС ФСИН. У пациентов группы сравнения, лечившихся I PXT, этот показатель в ПТД составил 66,7 \%, в ПТС ФСИН $56,7 \%(p<0,05)$. Та же самая тенденция установлена и по прекращению бактериовыделения на основании посева мокроты на питательные среды, притом что у больных, лечившихся ІІБ РХТ, в ПТД и ПТС ФСИН эти показатели были практически одинаковыми (90\% и 88,3\% соответственно; $p<0,05$ ).
Следовательно, ІІБ РХТ по показателю прекращения бактериовыделения через 3 мес. лечения одинаково высокоэффективен и при первичной лекарственной устойчивости (45 \%), и МЛУ (22,5\%) как у больных ПТД, так и у пациентов ПТС ФСИН (67,5\% и 33,3\% соответственно). Это, в первую очередь, связано с применением при ІІБ РХТ фторхинолонов, которые в комбинации с 4 основными противотуберкулезными препаратами (изониазидом, рифампицином, пиразинамидом и этамбутолом) и канамицимом (амикацином) высокоэффективны при высоком уровне лекарственной устойчивости МБТ.

В то же время у больных, лечившихся I PXT, в ПТД прекращение бактериовыделения наблюдалось в $60 \%$ случаев, а в ПТС ФСИН - в 48,3\%, что на $11,7 \%$ меньше $(p<0,05)$. Это в какой-то мере может быть объяснено более высоким уровнем первичной МЛУ МБТ у пациентов ПТС ФСИН, на которую 4 основных препарата практически не действуют.

Таким образом, в современных эпидемиологических условиях в РФ, при уровне первичной лекарственной устойчивости МБТ 36,9 \% и уровне МЛУ 17,3\% [4-6], только ІІБ РХТ обеспечивает высокую эффективность по показателю прекращения бактериовыделения в первые 3 мес. интенсивной фазы лечения, а I PXT показывает низкую эффективность и дальнейшее прогрессирование заболевания.

В табл. 5 представлены суммированные данные больных ПТД и ПТС ФСИН по частоте прекращения бактериовыделения в наблюдаемых группах в зависимости от первичной лекарственной чувствительности

Таблица 4

Эффективность лечения по показателям прекращения бактериовыделения по методу микроскопии и посева на питательные среды через 3 мес. химиотерапии

\begin{tabular}{|c|c|c|c|c|c|c|}
\hline \multirow[t]{3}{*}{ Лечебное учреждение } & \multirow[t]{3}{*}{ PXT } & \multirow[t]{3}{*}{ Абс. } & \multicolumn{4}{|c|}{ Прекращение бактериовыделения, $n$ (\%) } \\
\hline & & & \multicolumn{2}{|c|}{ по микроскопии } & \multicolumn{2}{|c|}{ по посеву } \\
\hline & & & MБT- & МБT+ & МБТ- & MБT+ \\
\hline \multirow[t]{2}{*}{ пТम } & ІІБ & 60 & $60(100)$ & - & $54\left(90,0 \pm 4,6^{*}\right)$ & $6\left(10,0 \pm 4,6^{*}\right)$ \\
\hline & I & 60 & $40(66,7 \pm 6,1)$ & $20(33,3 \pm 6,1)$ & $36\left(60,0 \pm 6,3^{*}\right)$ & $24\left(40,0 \pm 6,3^{*}\right)$ \\
\hline \multirow[t]{2}{*}{ птС ФСИн } & ІІБ & 60 & $60(100)$ & - & $53\left(88,3 \pm 4,1^{*}\right)$ & $7\left(11,7 \pm 4,1^{*}\right)$ \\
\hline & I & 60 & $34(56,7 \pm 6,4)$ & $26(43,3 \pm 6,4)$ & $29\left(48,3 \pm 7,7^{\star}\right)$ & $31\left(51,6 \pm 7,7^{\star}\right)$ \\
\hline
\end{tabular}

Примечание: * - p<0,05 при сравнении ІІБ и І РXТ. 
Таблица 5

Частота прекращения бактериовыделения, в зависимости от первичной лекарственной чувствительности МБТ, через 3 мес. химиотерапии

\begin{tabular}{|c|c|c|c|c|}
\hline РХТ & $\begin{array}{c}\text { Характер пер- } \\
\text { вичной ЛЧ МБТ }\end{array}$ & Абс. & МБТ-, $n(\%)$ & МБТ,$+ n(\%)$ \\
\hline ІІБ & ЛЧ & 53 & $53(100)$ & - \\
& МР & 10 & $10(100)$ & - \\
& ПР & 22 & $22(100)$ & - \\
\hline & МЛУ & 35 & $22(62,9 \pm 8,1)$ & $13(37,1 \pm 8,1)$ \\
\hline & ЛЧ & 52 & $52(100)$ & - \\
& МР & 13 & $9(69,2 \pm 12,8)$ & $4(30,8 \pm 12,8)$ \\
& ПР & 23 & $4(17,4 \pm 7,9)$ & $19(82,6 \pm 7,4)$ \\
& МЛУ & 32 & - & $32(100)$ \\
& & & &
\end{tabular}

МБТ через 3 мес. химиотерапии. Как следует из табл. 5 , через 3 мес. химиотерапии у больных основной группы, лечившихся ІІБ РХТ, прекращение бактериовыделения при сохраненной чувствительности МБТ, моно- и полирезистентности было констатировано в $100 \%$ случаев. В то же время показателен тот факт, что применение ІІБ РХТ позволило добиться прекращения бактериовыделения у 22 из 35 больных (62,9\%) с первичной МЛУ МБТ. За это время у больных группы сравнения, лечившихся I PXT, прекрашения бактериовыделения в $100 \%$ случаев удалось добиться только при сохраненной чувствительности МБТ. При монорезистентности этот показатель составил 62,2\%, при полирезистентности - 17,4\%, а при МЛУ ни у одного больного прекращения бактериовыделения не удалось добиться.

Следовательно, применение ІІБ РХТ у 120 впервые выявленных больных деструктивным туберкулезом легких в ПТД и ПТС ФСИН (при уровне первичной лекарственной устойчивости МБТ 55,8 \pm $4,5 \%$, монорезистентности $8,3 \pm 2,5 \%$, полирезистентности $18,3 \pm 3,5 \%$ и МЛУ 29,2 $\pm 4,1 \%$ ) позволяет существенно повысить эффективность лечения по показателю прекращения бактериовыделения, полностью преодолеть моно- и полирезистентность, а у почти $1 / 3$ пациентов - МЛУ.

Использование I PXT у 120 больных при аналогичном уровне первичной лекарственной устойчивости МБТ $(56,7 \pm 4,5 \%)$, монорезистентности $(10,8 \pm 2,8 \%)$, полирезистентности $(19,2 \pm 3,5 \%)$ и МЛУ $(26,7 \pm 4,0 \%)$ является эффективным только у больных с сохраненной чувствительностью МБТ. При монорезистентности он был эффективен у $2 / 3$ пациентов, при полирезистентности - только у 1/3, а при МЛУ І РХТ оказался абсолютно неэффективен.

В то же время из 55 больных с продолжающимся бактериовыделением, лечившихся 3 мес. I PXT, у 51 пациента $(92,7 \pm 3,5 \%)$ установлено нарастание лекарственной устойчивости МБТ к большему числу препаратов, в т. ч. резервных, что еще в 2000 г. было описано В.Ю.Мишиным и В.И.Чукановым [45] как индукция вторичной лекарственной устойчивости МБТ при лечении впервые выявленных больных туберкулезом легких I PXT.

Так, у 4 больных первичная монорезистентность трансформировалась в полирезистентность - у 2 па- циентов и в МЛУ - у 2. У 19 больных первичная полирезистентность перешла в МЛУ (к большему числу основных препаратов - у 7 и к сочетанию основных и резервных препаратов - у 12 пациентов). У 32 больных с первичной МЛУ только к основным препаратам сформировалась МЛУ к сочетанию основных и резервных, в т. ч. канамицину, протионамиду, циклосерину или парааминосалициловой кислоте (ПАСК), даже к тем лекарствам, которые они не получали.

Из представленных данных следует, что у 51 из 120 больных (42,5 \pm 4,5 \%), лечившихся I PXТ, установлено формирование вторичной лекарственной устойчивости МБТ, при этом у 7 пациентов впервые появилась МЛУ к основным противотуберкулезным препаратам, а у 44 - к сочетанию основных и резервных. У больных, лечившихся ІІБ РХТ, подобный феномен установлен не был.

Следовательно, I PX в лечении впервые выявленных больных деструктивным туберкулезом легких с высоким уровнем первичной МЛУ МБТ ведет к индукции и формированию МЛУ к основным и резервным препаратам, что является одним из главных факторов увеличения данного контингента пациентов в ПТД и противотуберкулезных учреждениях ФСИН.

В табл. 6 представлена частота закрытия каверн в легких через 3 мес. химиотерапии у больных в наблюдаемых группах.

Как видно из табл. 6 через 3 мес. лечения закрытие каверн в легких в основной группе, лечившихся ІІБ РХТ, как у больных ПТД (73,3 \%), так и у пациентов в ПТС ФСИН, было практически одинаковым, не смотря на более тяжелое течение туберкулеза легких в ПТС ФСИН $(p>0,05)$. У пациентов группы сравнения, лечившихся I РХТ, это показатель в ПТД составил 46,7 \%, в ПТС ФСИН - 36,7 \%, что соответственно в 1,6 и 1,9 раза меньше $(p<0,05)$. Следует отметить, что показатель закрытия каверн в легких $(46,7 \%)$ у больных, лечившихся I PХT в ПТС ФСИН, был на $10 \%$ ниже, чем у пациентов ПТД $(36,7 \% ; p>0,05)$. Это можно объяснить более тяжелым течение заболевания в ПТС ФСИН и меньшей эффективностью I PXT не только по показателю закрытия каверн, но и показателю прекращения бактериовыделения.

Побочные реакции в основной группе, лечившихся ІІБ РХТ, были выявлены у 23 из 120 больных $(19,2 \pm 3,6 \%)$, а в группе сравнения, лечившихся

Таблица 6

Частота закрытия каверн в легких через 3 мес. химиотерапии

\begin{tabular}{|c|c|c|c|c|}
\hline \multirow{2}{*}{$\begin{array}{c}\text { Лечебное } \\
\text { учреждение }\end{array}$} & \multirow[t]{2}{*}{ PXT } & \multirow[t]{2}{*}{ Абс. } & \multicolumn{2}{|c|}{ Закрытие каверн в легких, $n$ (\%) } \\
\hline & & & каверна- & каверна+ \\
\hline \multirow[t]{2}{*}{ птд } & ІІБ & 60 & $44\left(73,3 \pm 5,7^{*}\right)$ & $16\left(26,7 \pm 5,7^{\star}\right)$ \\
\hline & I & 60 & $28\left(46,7 \pm 6,3^{*}\right)$ & $32\left(53,3 \pm 6,4^{*}\right)$ \\
\hline \multirow[t]{2}{*}{ ПтС ФСИн } & ІІБ & 60 & $42\left(70,0 \pm 5,9^{*}\right)$ & $18\left(30,0 \pm 5,9^{*}\right)$ \\
\hline & I & 60 & $22\left(36,7 \pm 6,2^{*}\right)$ & $38\left(63,3 \pm 6,2^{*}\right)$ \\
\hline
\end{tabular}

Примечание: * - $p<0,05$ при сравнении ІІБ и I РХТ. 
I PXT, у 24 из 120 пациентов (20\%; $p>0,05)$. В группе больных, лечившихся ІІБ РХТ, у 22 пациентов было транзиторное повышение аминотрансфераз и у 1 - фотодерматоз, а в группе, лечившихся I PXT, у 20 - транзиторное повышение аминотрансфераз, у 4 - кожные аллергические реакции. Применение гепатопротекторов и десенсибилизирующих лекарств позволило у всех больных купировать побочные реакции без отмены назначенной комбинации препаратов.

После 3 мес. лечения и получения данных о лекарственной чувствительности МБТ по непрямому микробиологическому методу абсолютных концентраций проводилась коррекция химиотерапии. Больные, у которых удалось добиться прекращения бактериовыделения, вступали в фазу продолжения лечения в соответствии с Приказом МЗ РФ № 109 от 21.03 .03 [3]. У 13 из 120 больных (10,8 $\pm 2,8 \%)$ основной группы, лечившихся ІІБ РХТ, и у 55 из 120 пациентов $(45,8 \pm 4,5 \%)$ группы сравнения, лечившихся I PXT, проводилась коррекция химиотерапии, при этом отменялись основные препараты, к которым была выявлена устойчивость МБТ, и назначались резервные, к которым чувствительность сохранялась.

Следует подчеркнуть, что 45,8 \% больных со впервые выявленным деструктивным туберкулезом легких после окончания интенсивной фазы лечения I PXT нуждались в лечении комбинацией дорогостоящих резервных препаратов, в то время как только 10,8 \% пациентов, лечившихся ІІБ РХТ, нуждались в них, что в 4,2 раза меньше $(p<0,001)$.

Через 12 мес., при окончании курса лечения, у $94,2 \pm 2,1 \%$ (у 113 из 120) больных основной группы было достигнуто абациллирование, что всего на 5 \% больше числа пациентов с прекратившемся бактериовыделением через 3 мес. интенсивной фазы ІІБ PXT (94,2 $\pm 2,1 \%)$. Аналогичная ситуация была и в группе сравнения, где абациллирование произошло у $65,0 \pm 4,3 \%$ (у 78 из 120) больных, прирост составил $11 \%$ по сравнению с количеством пациентов с прекратившимся бактериовыделением через 3 мес. $(54,2 \pm 4,5 \%)$.

Следовательно, результативность интенсивной фазы химиотерапии у впервые выявленных больных деструктивным туберкулезом легких определяет эффективность всего основного курса лечения. В этих условиях только при ІІБ РХТ можно добиться высоких результатов клинического излечения и с меньшими экономическими затратами.

В табл. 7 представлены данные о клиническом излечении через 12 мес. и частоте развития ранних рецидивов через 2-3 года диспансерного наблюдения.

Клиническое излечение (нормализация клинических показателей, прекращение бактериовыделения по микроскопии и посеву мокроты на питательные среды, значительное рассасывание инфильтративных изменений и закрытие каверн в легких) через 12 мес. основного курса лечения в основной группе, получавшей в интенсивной фазе ІІБ РХТ, было установлено у 94,2 \% больных. В то же время в группе сравнения, получавшей в интенсивной фазе I PXT, клиническое излечение было достигнуто только у $65 \%$ пациентов, что на 29,2\% ниже $(p<0,05)$.

Необходимо отметить, что в группе сравнения через 12 мес. лечения в $35 \%$ случаев не удалось добиться клинического излечения. Процесс в легких неуклонно прогрессировал, сформировался фиброзно-кавернозный туберкулез легких с постоянным выделением МБТ с МЛУ к сочетанию основных и резервных препаратов, что требовало применения не только дорогостоящих резервных препаратов, но и дорогостоящих высокотехнологичных оперативных вмешательств и длительного стационарного лечения.

Ранние рецидивы через 2-3 года после клинического излечения были диагностированы у больных основной группы, получавших в интенсивной фазе ІІБ РХТ, в 2,6 \% случаев (у 3 из 113 пациентов), а у пациентов группы сравнения, получавших в интенсивной фазе I PXT, - в 20,5 \% (у 16 из 78), что в 7,8 раза выше $(p<0,001)$.

При оценке в целом состояния лиц в наблюдаемых группах через 2-3 года диспансерного наблюдения было констатировано, что из 120 больных основной группы, лечившихся в интенсивной фазе ІІБ PXT, у $110(91,7 \pm 2,5 \%)$ пациентов достигнуто стойкое клиническое излечение, у $3(2,5 \pm 1,4 \%)$ - был ранний рецидив болезни и у $7(5,8 \pm 2,5 \%)$ - сформировался фиброзно-кавернозный туберкулез легких, при этом 5 больных уже прооперированы с хорошим эффектом. В то время как из 120 больных группы сравнения, получавших в интенсивной фазе I PXT, только у $62(51,7 \pm 4,5 \%)$ пациентов установлено стойкое клиническое излечение, но у 16 (13,3 \pm $3,7 \%)$ - выявлен ранний рецидив и у $42(35,0 \pm$ $4,3 \%)$ - развился хронический фиброзно-кавернозный туберкулез, при этом 9 пациентов умерли вследствие осложненного и прогрессирующего течения туберкулеза.

Следовательно, высокая стойкость клинического излечения и низкая частота ранних рецидивов у больных со впервые выявленным туберкулезом легких значительно выше у больных, которые в интенсивной фазе лечения получали ІІБ РХТ, по сравнению с пациентами, лечившимися I PXT, который в современных эпидемиологических условиях является малоэффективным, с высокой частотой возникновения ранних рецидивов и высоким уровнем вторичной МЛУ МБТ, что, в конечном итоге, ведет к формированию неблагоприятной эпидемиологической ситуации по туберкулезу в РФ.

Таблица 7

Клиническое излечение через 12 мес. лечения и частота ранних рецидивов болезни через 2-3 года диспансерного наблюдения

\begin{tabular}{|l|r|r|r|}
\hline $\begin{array}{c}\text { РХТ интен- } \\
\text { сивной фазы }\end{array}$ & Абс. & $\begin{array}{r}\text { Клиническое излечение } \\
\text { через } 12 \text { мес. }\end{array}$ & $\begin{array}{r}\text { Ранние рецидивы } \\
\text { через 2-3 года }\end{array}$ \\
\hline ІІБ & 120 & $113\left(94,2 \pm 2,1^{*}\right)$ & $3\left(2,6 \pm 1,5^{\star}\right)$ \\
\hline I & 120 & $78\left(65,0 \pm 4,3^{*}\right)$ & $16\left(20,5 \pm 4,4^{*}\right)$ \\
\hline
\end{tabular}

Примечание: * ${ }^{*} p<0,05$ при сравнении ІІБ и I РХТ. 
Таким образом, результаты рандомизированного контролируемого клинического исследования доказали, что ІІБ РХТ, как в гражданских, так и пенитенциарных противотуберкулезных учреждениях, является экономически обоснованной инновационной технологией лечения впервые выявленных больных деструктивным туберкулезом легких, имеющей высокую AI-категорию по критериям доказательной медицины. И это в условиях неуклонно растущего уровня первичной лекарственной устойчивости МБТ, в т. ч. МЛУ, которая в настоящем исследовании составляла 22,5-33,3 \%. При этом комбинация изониазида, рифампицина, пиразинамида, этамбутола, фторхинолона, канамицина или амикацина обладает выраженным бактерицидным действием, в т. ч. на штаммы МБТ с МЛУ, что позволяет добиться стойкого клинического излечения практически у всех больных с моно- и полирезистентностю, а также более чем у половины с МЛУ.

В то же время I PXT, состоящий из комбинации изониазида, рифампицина, пиразинамида, этамбутола или стрептомицина, в условиях высокого уровня первичной лекарственной устойчивости МБТ, в т. ч. МЛУ (22,5-33,3 \%), является не только малоэффективным, но и вызывающим при лечении формирование вторичной МЛУ МБТ к сочетанию основных и резервных препаратов. При этом более чем у $1 / 3$ пациентов болезнь не излечивается, и у них формируется фиброзно-кавернозный туберкулез легких с постоянным выделением МЛУ МБТ, что требует сушественных экономических затрат на длительный курс химиотерапии резервными препаратами и дорогостоящие оперативные вмешательства. При этом более чем в $14 \%$ случаев развиваются рецидивы заболевания. Именно данный контингент является основным источником туберкулезной инфекции и способствует заражению здорового населения и контингента пенитенциарных учреждений ФСИН, что будет вести к нарастанию первичной лекарственной устойчивости МБТ, в т. ч. МЛУ, снижению эффективности лечения и серьезному ухудшению эпидемиологической ситуации в РФ.

\section{Заключение}

1. У впервые выявленных больных деструктивным туберкулезом легких в гражданских и пенитенциарных противотуберкулезных учреждениях при уровне МЛУ 22,5-33,3 \% применение в интенсивной фазе лечения ІІБ РХТ позволяет добиться прекращения бактериовыделения по микроскопии мокроты в 100 \% случаев и по посеву в 89,2 \%, при этом закрытие каверн в легких составляет 71,7\%.

2. У впервые выявленных больных деструктивным туберкулезом легких в гражданских и пенитенциарных противотуберкулезных учреждениях при уровне МЛУ 22,5-33,3 \% применение в интенсивной фазе лечения I PXТ позволяет добиться прекращения бактериовыделения по микроскопии мокроты в 54,2 \% случаев и по посеву - в 45,8 \%, при этом закрытие каверн в легких составляет $45,8 \%$.

3. У впервые выявленных больных деструктивным туберкулезом легких в гражданских и пенитенциарных противотуберкулезных учреждениях при уровне МЛУ 22,5-33,3 \% клиническое излечение при использовании в интенсивной фазе лечения ІІБ режима химиотерапии установлено в 94,2\% случаев, а ранние рецидивы диагностированы только у 2,6 \% пациентов. В то время как при использовании I РХТ клиническое излечение достигнуто у $65 \%$ пациентов, при этом у 55 \% больных констатировано формирование фибрознокавернозного туберкулеза с выделением МЛУ МБТ к сочетанию основных и резервных препаратов, а ранние рецидивы выявлены у $20,5 \%$ пациентов.

\section{Литература}

1. Лекции по фтизиопульмонологии / Мишин В.Ю., Стрелис А.К., Чуканов В.И.и др. М.: МИА; 2006.

2. Мишин В.Ю. Химиотерапия туберкулеза легких. Пульмонология 2008; 3: 5-14.

3. Перельман М.А. (ред.). Фтизиатрия: Нац. руководство. М.: ГЭОТАР-Медиа; 2007.

4. Хоменко А.Г. (ред.). Химиотерапия туберкулеза легких. М.: Медицина; 1980.

5. Приказ МЗ РФ от 21 марта 2003 г. № 109. "О совершенствовании противотуберкулезных мероприятий в Российской федерации. М.; 2003.

6. Ресурсы и деятельность противотуберкулезных учреждений. Основные показатели за 2008-2010 годы: Статичтические материалы / Гордина А.В., Зайченко Н.М., Кучерявая Д.А. и др. М.; 2011.

7. Сон И.М., Нечаева О.Б., Стерликов С.А. и др. Отраслевые показатели противотуберкулезной работы в 20092010 гг. Статистические материалы. М.; 2011.

8. Шилова М.В. Туберкулез в России в 2009 году. М.; 2010.

9. Мишин В.Ю. Туберкулез легких с лекарственной устойчивостью возбудителя. М.: ГЭОТАР-Медиа; 2007.

10. Ваниев Э.В. Эффективность химиотерапии впервые выявленных больных деструктивным туберкулезом легких с лекарственной устойчивостью МБТ: Автореф. дис. ... канд. мед. наук. М.; 2008.

11. Ерохин В.В., Мишин В.Ю., Чуканов В.И., Гиллер Б.Д. Казеозная пневмония. М.: Медицина; 2008.

12. Кибрик Б.С., Челнокова О.Г. Остропрогрессирующие деструктивные формы туберкулеза легких. Ярославль; 2005.

13. Кононеи А.С. Эффективность лечения лекарственноустойчивого туберкулеза легких в исправительных учреждениях ФСИН России: Автореф. дис. ... д-ра мед. наук. М.; 2009.

14. Мишин В.Ю., Мякишева Т.В., Мишина А.В. и др. Химиотерапия впервые выявленных больных туберкулезом легких в современных эпидемиологических условиях. Омск. науч. вестн. 2009; 1 (84): 86-90.

15. Кононеи А.С. Методические рекомендации по химиотерапии впервые выявленных больных деструктивным туберкулезом легких и больных рецидивами деструктивного туберкулеза с бактериовыделением в учреждениях уголовно-исполнительной системы Российской Федерации. М.; 2006. 
16. Ваниев Э.В., Васильева И.А., Абдуллаев Р.Ю. и др. Использование фторхинолонов в интенсивной фазе лечения впервые выявленных больных деструктивным туберкулезом легких. Пробл. туб. и бол. легких 2008; 10: $57-60$.

17. Голубева Л.И., Мишин В.Ю., Григорьев Ю.Г. и др. Медикаментозные осложнения при лечении I, IIA и ІІБ режимом химиотерапии больных туберкулезом легких. Туб. и бол. легких 2011; 4: 106.

18. Келасова Н., Аксенова В. Эффективность лечения препаратом Ломекомб молодых больных туберкулезом легких. Врач 2007; 8: 32-33.

19. Мишин В.Ю., Кононеи А.С., Голубева Л.Н. и др. Эффективность нового стандартного режима химиотерапии с использованием фторхинолонов в лечении больных впервые выявленным деструктивным туберкулезом легких. В кн.: Материалы Научной сессии, посвящ. 85летию ЦНИИТ РАМН "Актуальные проблемы туберкулеза и болезней легких". М.; 2006. 109-110.

20. Мишин В.Ю. Медикаментозные осложнения комбинированной химиотерапии туберкулеза легких. М.: МИА; 2007.

21. Мишин В.Ю., Мякишева Т.В., Амараева Л.В. и др. Эффективность лечения больных деструктивным туберкулезом легких больных при парентеральном и пероральном применения противотуберкулезных препаратов. Пульмонология 2011; 1: 55-59.

22. Мишин В.Ю., Кононеи А.С. Эффективность ІІБ режима химиотерапии с использованием левофлоксацина при лечении впервые выявленных больных туберкулезом легких. В кн.: XXI Национальный конгресс по болезням органов дыхания: Сборник трудов. Уфа; 2011. 309.

23. Падейская Е.Н. Таваник - возможности в терапии туберкулеза. Качеств. клин. практ. 2003; 1: 4-12.

24. Паролина Л.Е., Казимирова Н.Е., Амирова З.Р. Фторхинолоны в лекарственной терапии прогрессирующего туберкулеза. В кн.: XVII Национальный конгресс по болезням органов дыхания: Сборник трудов. Казань; 2007. 190.

25. Решетняк В.И., Соколова Г.Б. Роль фторхинолонов в лечении туберкулеза. Антибиотики и химиотер. 2003; 7: 5-11.

26. Чуканов В.И., Васильева И.А., Ваниев Э.В. Эффективность применения препаратов фторхинолонового ряда в лечении впервые выявленных больных туберкулезом легких, выделяющих лекарственно-устойчивые микобактерии. В кн.: Актуальные вопросы клинической и экспериментальной медицины: Сборник тезисов науч.-практ. конф. СПб.; 2006. 291

27. Чуканов В.И., Васильева И.А., Ваниев Э.В. Фторхинолоны в лечении впервые выявленных больных лекарственно-устойчивым туберкулезом легких. Consilium medicum 2007; 7 (10): 854-856.

28. Berning $S$. The role of fluorquinolones in tuberculosis today. Drugs 2001; 61 (1): 9-18.

29. Ginsburg A., Grosset J., Bishai W. Fluoroquinolones, tuberculosis and resistance. Lancet Infect. Dis. 2003: 3: 432-442.

30. Hи Y., Coates A., Mitchison D. Sterilizing activities of fluoroquinolones against rifampin-tolerant populations of Mycobacterium tuberculosis. Antimicrob. Agents Chemother. 2003; 47: 653-657.

31. Low D. Fluoroquinolones for treatment of communityacquired pneumonia and tuberculosis: putting the risk of resistance into perspective. Clin. Infect. Dis. 2009; 48 (10): $1361-1363$
32. Yew W.W., Chan C.K., Leung C.C. Comparative roles of levofloxacin and ofloxacin in the treatment of multidrugresistant tuberculosis: preliminary results of a retrospective study from Hong Kong. Chest 2003; 124 (4): 1476-1481.

33. Алябина М.Г. Организация контролируемых клинических исследований по химиотерапии туберкулеза в Сoветском Союзе и их научно-практическое значение: Автореф. дис. ... Д-ра мед. наук. М.; 1975.

34. Григорьев Ю.Г., Мишин В.Ю., Завражнов С.П. и др. Эффективность модернизированного ІІБ режима химиотерапии при парентеральном введении противотуберкулезных препаратов у впервые выявленных больных деструктивным туберкулезом легких с позиции медицины доказательств. Туб. и бол. легких (IX съезд фтизиатров России) 2011; 4: 109.

35. Кононеи А.С., Мишин В.Ю., Голубева Л.И. и др. Сравнительная эффективность ІІБ и І режимов химиотерапии у впервые выявленных больных туберкулезом легких в пенитенциарных учреждениях с позиции медицины доказательств. Туб. и бол. легких (IX съезд фтизиатров России) 2011; 4: 203-204.

36. Левашов Ю.Н., Мишин В.Ю., Краснов В.А. и др. Многоцентровые исследования эффективности ІІб режима химиотерапии с использованием комбинированного препарата ломекомб при лечении впервые выявленных больных туберкулезом легких с бактериовыделением. В кн.: XVI Российский нац. конгресс "Человек и лекарство": Тезисы докладов. М.; 2009. 157.

37. Мишин В.Ю., Кононеи, А.С., Голубева Л.И. Эффективность и переносимость нового стандартного режима химиотерапии с использованием фторхинолонов у впервые выявленных больных деструктивным туберкулезом легких. Рус. мед. журн. 2007; 15 [18 (299)]: $1302-1305$.

38. Мишин В.Ю. Лечение впервые выявленных больных туберкулезом легких на основе принципов доказательной медицины. Consilium Medicum 2008; 10 (3): 20-25.

39. Mishin V., Levashov J., Elkin A. et al. Multicenter randomized clinic study of new standard chemotherapy regiment for new cases patients of pulmonary tuberculosis executed in Russia regions with high level of multiple drug resistance (MDR). Eur. Respir. J. 2009; 34 (Suppl. 53): 465s. P.2618.

40. Мишин В.Ю., Левашов Ю.Н., Елькин А.В. и др. Многоцентровое рандимизированное клиническое исследование нового стандартного режима химиотерапии у впервые выявленных больных туберкулезом легких в регионах с высоким уровнем первичной множественной лекарственной устойчивости. В кн.: II Научнопрактическая конф. Москвы и Московского региона "Актуальные вопросы респираторной медицины". М.; 2010. 48-49.

41. Мишин В.Ю., Григорьев Ю.Г., Завражнов С.П. и др. Сравнительная эффективность ІІБ и I режима химиотерапии у впервые выявленных больных туберкулезом легких с высоким риском развития первичной лекарственной устойчивости с позиций медицины доказательств. Туб. и бол. легких 2011; 5: 50-51.

42. Мишин В.Ю., Мякишева Т.В., Мишина А.В. Эффективность различных методов введения противотуберкулезных препаратов во ІІБ режиме химиотерапии у впервые выявленных больных туберкулезом легких с позиций медицины доказательств. Практ. мед. 2011; 3 (51): 63-67.

43. Guidelines for the treatment of tuberculosis. American Thoracic Society, Centers for Disease Control and 
Prevention and Infectious Diseases Society of America; 2004.

44. Treatment of tuberculosis guidelines, $4^{\text {th }}$ ed. Geneva: WHO; 2009.

45. Мишин В.Ю., Чуканов В.И. Феномен индукции нарастающей поливалентной лекарственной резистентности микобактерий при стандартных курсах химиотерапии. В кн.: Х Национальный конгресс по болезням органов дыхания: Сборник резюме. СПб.; 2000. 293.

\section{Информация об авторах}

Мишин Владимир Юрьевич - д. м. н., проф., декан факультета пенитенциарной медицины, зав, кафедрой фтизиопульмонологии ГБОУ ВПО "Московский государственный медико-стоматологический уни верситет" Минздравсоцразвития России, тел.: (495) 694-05-63; e-mail: mishin.vy@mail.ru

Кононец Александр Семенович - д. М. Н., проф., зав. кафедрой пенитенциарной медицины ГБОУ ВПО "Московский государственный медико-стоматологический университет" Минздравсоцразвития России тел.: (495) 694-05-63 